\title{
POSSIBILITIES OF THE METHOD OF AN X-RAY FLUORESCENCE ANALYSIS WHEN EVALUATING ESSENTIAL ELEMENT CONCENTRATIONS IN FOOD RAW MATERIALS OF PLANT ORIGIN
}

\author{
Tatyana K. Krupskaya, Ludmila Loseva, Slavomir Anufrik \\ Yanka Kupala State University of Grodno, Grodno, Republic of Belarus
}

\begin{abstract}
The population growth on the earth and the prospects for its increasing put forward a problem of providing clear drinking water to society and valuable fodder, food and energy resources on one of the first places every 25-30 years. The acuteness of the problem becomes more and more appreciable every year as mankind consumes the potential energy of the biosphere almost 10 times faster than its natural accumulation occurs by green plants during photosynthesis. Thus, the task of searching plant raw materials, which would become a source of biologically active substances and have positive influence on the health of animals and persons, is especially relevant today.
\end{abstract}

Keywords: $x$-ray fluorescence analysis, essential element, food raw materials

\section{INTRODUCTION}

Many plants, vegetable, fruit and cereal cultures are rich in biologically active substances, capable of accumulating macro - and microelements and be natural antioxidants. Microelements have an influence on a variety of physiological functions of an organism from intracellular metabolism to reproduction. The ability of plants to accumulate macro- and microelements and also form biologically active substances represents perspective possibilities of using these plants not only in medicine as means of preventing microelementoses, but also in the food industry for creating the products of a functional purpose. In addi- 
tion, such plants can find application as animal feed and biofertilizers and in agriculture as well [1-4].

Plants contain more microelements than animals. If food is monotonous, sustained excess or deficiency of the same microelements can significantly impact on a person and his health. Until now microelements have rarely been taken into account at the appointment of a medical diet. It is absolutely necessary to consider their influence. The purpose of the present study is to show the possibility of using higher aquatic plants as the sources of essential elements.

\section{MATERIALS AND METHODS}

The regulation of the microelement composition of food raw materials and food products is necessary in modern conditions. In recent years increasing attention has been paid to the method of an X-ray fluorescence. An X-ray fluorescence analysis (XRFA) belongs to a multielement category. This method is based on measuring the spectrum, obtained by an X-ray radiation impact on the investigated material (the source of radiation is an X-ray tube). When transiting to the ground state the atoms excited by radiation emit the photoelectrons of strictly defined energies being taken into account for a spectral analysis. The spectrum of the studied elements depends on the current strength and voltage on a tube: $10 \mathrm{kV}$ for light elements, $40-50 \mathrm{kV}$ for heavy ones. Lower detection limit depends on the element atomic number, for example, for phosphorus -0.01 percent of the tested sample mass.

The feature of an X-ray fluorescence method, which favorably differs from other physical methods of analysis, is its high interference immunity. XRFA is very effective at the determination of the biological value of plant food raw materials (vegetables, fruits, grains). Using this method the Brazilian scientists defined the content of potassium, calcium, iron, copper and zinc in potatoes, bananas, salad, rice, beans and oranges. Great social significance has arisen from the results of researches on the microelement value of yakon, sweet potato and potatoes using the XRFA of the Chinese specialists. They revealed a high level of the content of $\mathrm{K}, \mathrm{Fe}, \mathrm{Ca}, \mathrm{Mg}, \mathrm{Mn}$ and $\mathrm{Cu}$, which is the justification for expanding the production of root crops in China. With the consideration of a high nutritional product value, comparable to rice and flour, it can provide the solution of food shortage problem [5-8].

The analysis of the samples of vegetables, grains and food concentrates was conducted according to the approved and registered "Technique of measuring the mass fraction of chemical elements - iron, cadmium, potassium, calcium, 
manganese, copper, arsenic, nickel, lead, sulfur, strontium, titanium, chromium and zinc in the samples of plant and animal origin by an X-ray fluorescence method using the spectrometer of X-ray radiation energies SER-01" (MVEN-2009).

Sample preparation was performed in accordance with this technique. The $\mathrm{X}$-ray fluorescence analysis of samples was carried out on an X-ray fluorescence analyzer ElvaX SER-01. For the microelement composition analysis the samples were weighed, brought to an air-dry state (in a drying chamber at a temperature of $65^{\circ} \mathrm{C}$ ), crushed and sifted through a sieve with a mesh size of $1 \mathrm{~mm}$. An $80-100 \mathrm{mg}$ sample was treated with a special solution for forming tablets, placed in a compression mold and pressed at a pressure of 1-1.2 $\mathrm{HPa}$ in tablets for an X-ray fluorescence analysis. The duration of one sample analysis did not exceed 30 minutes. To confirm the reliability of results, the prepared samples (tablets) were studied in different points of two surfaces (for changing the area exposed to X-rays) before obtaining a stable result. Method precision control was carried out in accordance with the above mentioned technique (MVEN-2009). Processing the results of studying the spectra of an $\mathrm{X}$-ray fluorescence was fulfilled using a personal computer, the data obtained were processed by programs MK_RE_06, MO Excel.

\section{RESULTS AND DISCUSSION}

In the course of research work the samples of vegetables most common to the Republic of Belarus were investigated on the content of macro - and microelements.

The results obtained are shown in Table 1 page 104.

As can be seen from the presented data, vegetables contain essentially significant microelements: zinc in concentrations from $1.07 \mathrm{mcg} / \mathrm{g}$ to $9.49 \mathrm{mcg} / \mathrm{g}$, copper - from $0.34 \mathrm{mg} / \mathrm{g}$ to $1.88 \mathrm{mcg} / \mathrm{g}$, iron - from $1.95 \mathrm{mcg} / \mathrm{g}$ to $12.75 \mathrm{mcg} / \mathrm{g}$; macroelements: potassium - from $1060.57 \mathrm{mcg} / \mathrm{g}$ to $2838.47 \mathrm{mcg} / \mathrm{g}$, calcium from $110.28 \mathrm{mcg} / \mathrm{g}$ to $989.59 \mathrm{mcg} / \mathrm{g}$ and heavy metals: cadmium, lead, strontium - in trace quantities. Measurement errors do not exceed $30 \%$. 
Table 1. Concentrations of macro - and microelements in vegetables

$\mathrm{mcg} / \mathrm{g}$

\begin{tabular}{lccccc}
\hline \multirow{2}{*}{ Product name } & \multicolumn{5}{c}{ Element concentration in product } \\
\cline { 2 - 6 } & Potassium & Calcium & Iron & Copper & Zinc \\
\hline Potatoes & 2838.47 & 119.49 & 12.75 & 1.50 & 2.58 \\
\hline Onion (bulb) & 1223.35 & 391.99 & 8.67 & 1.07 & 9.49 \\
\hline Onion (feather) & 1359,21 & 989,59 & 2,58 & 0,48 & 1,07 \\
\hline Carrot & 1068.91 & 122.48 & 3.41 & 0.65 & 1.59 \\
\hline Beet & 2447.95 & 110.28 & 8.16 & 1.88 & 4.54 \\
\hline White cabbage & 1616.41 & 140.56 & 2.87 & 0.62 & 1.92 \\
\hline Radish & 1060.57 & 121.63 & 1.95 & 0.34 & 1.98 \\
\hline
\end{tabular}

The greatest element contents are observed: for zinc - in the samples of bulb onions and beets, copper - in the samples of potatoes and beets, iron - in potatoes, bulb onions and beets, potassium - in potatoes and beets, calcium - in the samples of onion. Thus, from the nutrition science standpoint potatoes, onions and beets are some of the most biologically valuable vegetable cultures growing on the territory of Belarus.

The analysis of the concentrations of a broader micro- and macroelement spectrum in various grains was carried out. The obtained data on the content of bioelements in a raw material and ready food products are presented in Table 2.

Table 2. Concentrations of macro - and microelements in grains

$\mathrm{mcg} / \mathrm{g}$

\begin{tabular}{lccccc}
\hline \multirow{2}{*}{ Grain name } & \multicolumn{5}{c}{ Element concentration in product } \\
\cline { 2 - 6 } & Potassium & Calcium & Iron & Copper & Zinc \\
\hline Pea & 4372.10 & 316.15 & 70.27 & 14.85 & 26.52 \\
\hline Oats & 747.58 & 379.74 & 52.68 & 3.32 & 25.67 \\
\hline Wheat & 1806.20 & 253.72 & 45.01 & 5.42 & 31.75 \\
\hline Rye & 2303.82 & 338.62 & 38.45 & 3.72 & 32.37 \\
\hline Barley & 2171.21 & 320.98 & 66.30 & 6.61 & 34.47 \\
\hline Buckwheat & 1658.42 & 149.55 & 18.59 & 6.34 & 18.18 \\
\hline
\end{tabular}


As can be seen from the presented data, the greatest contents are observed for: potassium - in pea grain $(4372.10 \mathrm{mcg} / \mathrm{g})$, calcium - in oats grain (747.58 mcg/g), iron - in peas and barley $(70.27 \mathrm{mcg} / \mathrm{g}$ and $66.30 \mathrm{mcg} / \mathrm{g})$, copper - in peas $(14.85 \mathrm{mcg} / \mathrm{g})$, zinc - in barley grain $(34.47 \mathrm{mcg} / \mathrm{g})$. Measurement errors do not exceed $30 \%$. There are heavy metals nickel, lead and tin in this raw material as well.

Food concentrates on the basis of various grains were investigated for the contents of essentially significant microelements. There have been revealed the concentrations of bioelements (zinc in concentration from $7 \mathrm{mcg} / \mathrm{g}$ to 36 $\mathrm{mcg} / \mathrm{g}$, copper in concentration from $0.7 \mathrm{mcg} / \mathrm{g}$ to $5 \mathrm{mcg} / \mathrm{g}$, iron in concentration from $17 \mathrm{mcg} / \mathrm{g}$ to $31 \mathrm{mcg} / \mathrm{g}$, selenium in concentration from $0.2 \mathrm{mcg} / \mathrm{g}$ to $1 \mathrm{mcg} / \mathrm{g}$, sulfur in concentration from $876 \mathrm{mcg} / \mathrm{g}$ to $3000 \mathrm{mcg} / \mathrm{g}$ ) and macroelements (potassium in concentration from $500 \mathrm{mcg} / \mathrm{g}$ to $3100 \mathrm{mcg} / \mathrm{g}$, calcium in concentration from $99 \mathrm{mcg} / \mathrm{g}$ to $420 \mathrm{mcg} / \mathrm{g}$ ) in them. Measurement errors do not exceed $30 \%$.

Comparing the obtained data, we can draw a conclusion about the losses of such elements as calcium, potassium, zinc and copper when processing food raw materials (grains). Thus, it is necessary to improve preparation recipes and develop the new ways of enriching ready food products with vital elements for persons. The method of an X-ray fluorescence spectra analysis can be successfully applied for controlling product quality.

\section{CONCLUSION}

Thus, the method of an X-ray fluorescence analysis allows standardizing and controlling the content of minerals and microelements in food concentrates. The satisfactory coincidence of microelement research results in the different groups of vegetables, cereals and food concentrates by the method of an X-ray fluorescence has been obtained during the sample analysis, which allows using XRFA method for micronutrient content control in a technological process and monitoring studies of an actual nutrition. It has been established that the investigated varieties of vegetables and grains significantly differ on the content of calcium, potassium, copper, zinc and iron. This suggests a differentiated approach to the use of research results obtained with the help of XRFA when determining a nutritional value of food products being present on the RB market. 


\section{REFERENCES}

1. Kabata-Pendias H. (1989). Microelements in soils and plants, 83-98.

2. Abutolybov M.G. (1961). Trace Significance of microelements in plant growing, 116.

3. Shkolnik M.Y. (1950). Significance of microelements in plant life and agriculture, 97-98.

4. Vlasyuk P.A., Zhidkov V.A., Ivchenko V.I., Klimovitskaya Z.M., Okhrimenko M.F., Rudanova E.V., Sidorshina T.N. (1983). Participation of microelements in plant metabolism. Biological role of microelements, 87.

5. Revenko A.G. (1994). X-ray fluorescence analysis of natural materials: monograph. Resp. Ed. V.P. Afonin, 263 p.

6. Perring L., Blank J. (2008). Validation of quick measurement of mineral nutrients in milk powders: comparison of energy dispersive X-ray fluorescence with inductively coupled plasma-optical emission spectroscopy and potentiometry reference methods. Sens. \& Instrumen. Food Qual, 2, 254-261.

7. Vives A.E.S. et al. (2006). Synchrotron radiation total reflection X-ray fluorescence (SR-TXRF) for evaluation of food contamination. J. Radioanal. Nucl. Chem., 270, 1, 147-53.

8. Yue Wang, Guojun Shi, Bo Yuan, Sichuan Xu. (2013). Chemical Elemental Compositions and Nutrition Quality of Yacon, Sweet Potato and Potato. Journal of Modern Agriculture, 2, 2, 21-27.

\section{Address for correspondence:}

Tatyana Krupskaya

Yanka Kupala State University of Grodno

22 Ogeshko street

Grodno, Belarus, 230023

E-mail: fxmioos@mail.ru 